\section{Fabian tactics}

\author{
John Godfrey
}

\begin{abstract}
Europe's Environment: The Dobrís Assessment. Edited by David Stanners and Philippe Bourdeau. European Environment Agency: 1995. Pp. 676. £47, ECU55 (pbk). UK distributor, Earthscan. Shaping National Responses To Climate Change: A Post-Rio Guide. Edited by Henry Lee. Island: 1995. Pp. 303. \$48 (hbk); \$24.95 (pbk). UK distributor, Earthscan.

Environmental Policy and Industrial Innovation: Strategies in Europe, the US and Japan. By David Wallace. Royal Institute of International Affairs/Earthscan. Pp. 282. £32.50 (hbk); £14.95 (pbk).
\end{abstract}

THE change in the climate that is probably now afoot is new in an important respect apart from that of being the first to be manmade. The earlier changes happened before most habitats worldwide were dominated by human action. Major changes have previously been marked by accelerated evolutionary adaptation as well as by increased extinction. We can expect the change ahead to cause more extinction than evolution.

So the systematic outline in the monumental Europe's Environment of environments as they now are gives a welcome baseline for one continent by which to judge what is to come. It was produced by the European Environment Agency Task Force at the behest of all of Europe's environment ministers. The large-format volume is beautifully produced, although some illustrations lack even a brief explanation.

Some chapters are masterly short surveys in their own right. That on fishing and aquaculture outlines possible changes to the European Union's Common Fisheries Policy, which has failed so far in the essential task of conserving an inexorably overexploited common resource. No prescription is given, but it is clear that a solution must be found in better control of the effort put into the catching of fish rather than, as in the past, regulating what may be officially landed. The chapter on climate change is about as good an introduction as could be encompassed in a bare ten pages. It barely mentions, however, that the European Commission has been trying to reach agreement on tax instruments to stabilize carbon dioxide emissions at 1990 levels by 2000. The proposal for a carbon tax has been stultified by industrial objections to the effect it would have on international competitiveness, and by political response to this. The regressive nature of the tax is also of political concern, exacerbated by poorer consumers spending a higher proportion of their income on fuel and likely to vote accordingly.

This theme is taken up more thoroughly in Shaping National Responses to Climate Change. It gives the views of a sensitive group of US scholars on how the diverse domestic and international interests of different countries might be best accommodated to make solutions possible, rather than merely desirable. It is refreshing to read their acknowledgement that US environmental and energy policies have been particularly costly or ineffective, or both.

One chapter asks how a policy that would burden countries' economies could gain their voluntary support. It argues that the adoption of carbon taxes would not generate new vested interests that could then impede further progress, as the use of tradeable quotas would tend to do. The Organization for Economic Cooperation and Development (OECD) agrees that a tax should be the main mechanism for controlling greenhouse gases, but that a high tax applied in the countries of the OECD alone would shift carbonintensive industries to poorer countries. Weaker regulation there might well mean that emissions actually rise.

Even if this problem can be overcome, there remains that of making an eco-tax attractive enough to be adopted while large enough to be effective. As this is not dealt with convincingly, a more subtle variant of a tax to help stabilize the climate seems worth exploring. As industry needs predictable, and at best stable, costs in order to invest rationally, it would find a tax that delivered more stable energy prices attractive. Such a tax would have to be varied in rate in inverse relation to the price of carbon fuels. In this way, the income from the tax would be greatest when the world price of these fuels was low. As the price of oil fluctuates greatly, dampening oil's oscillations would be of most help to industry. It would bring in enough revenue to reduce taxes on labour, so encouraging employment and reducing welfare costs.

A direct public benefit of an economically counter-cyclical tax would be steadier motivation to invest for a lower rate of carbon use, by any technically feasible means. A second benefit would be that if oil were to be taxed overall more than its carbon content would warrant, then oil would last longer. More of its value as a highly mobile fuel would be realized by the price it would then get. A third benefit would follow if the tax were paid into a fund to be used at a steady rate to finance the conservation and more efficient use of energy, and research and development directed towards energy projects that could be sustained.

As well as research into avoiding severe change to our climate, we also need to prepare to ameliorate its worst effects. If global warming becomes an acute problem, the market mechanism will work, because research (say into genetically engineered crops and animals adapted to harsh conditions) would pay in the short term that markets recognize. By then it will be too late for anything close to an optimal response to the problem. Even if the climate does not change as much as most now anticipate, such research will be valuable in parts of the world already short of food, which will have even less with the increase in the world's population. This proposal for what might be called a negative-feedback carbon tax could be used to relaunch the European Union's abortive carbon tax.

Innovation of many kinds will be essential. More spending of public money is not by itself a panacea. Environmental Policy and Industrial Innovation uses the recent history of what has been done about key environmental problems by the richest countries to show which policies work best, and why, and which are ineffective and thus often disastrously expensive. This book will be compelling reading for anyone interested in the practical solution of environmental problems, and should be compulsory for those with responsibility.

The United States and Germany have had the most visible environmental movements. As a result they have had tough environmental policies, but these have been adversarial and inconsistent. So their policies have been comparatively costly failures because they have generated political reaction, and because of poor relations between government and industry. In the case of Germany this is odd, as on other issues government and industry relate well. By contrast, Japan and Denmark have had tough policies that have worked well, for different reasons. Japan's local governments have led the way to the development of targets that have been steadily tightened. Industry has known what was coming and prepared for it, often by innovation. In Denmark, industry has long accepted the deeply rooted environmental ethos. The Netherlands, however, is making rapid progress by combining two synergistic policies. The government has an overarching strategy for sustainable development, linked to detailed agreements between government and industry that are beginning to achieve the strategy's ends.

David Wallace leads us away from the usual slanging match between the advocates and opponents of environmental regulation. His evidence is that tough regulations that are well informed about industry lead to beneficial innovation. Unrealistic regulations are indeed a costly burden. In California, the state government forced car manufacturers by legislation to market electric cars in order to be allowed to sell the usual kind. The effect is that there are now electric second, or third, cars parked alongside the gas guzzlers.

Taken together, these books suggest possible ways to encourage international collaboration that might forestall major alteration of our climate; but they only hint at how, if this fails, richer countries may instead act to mitigate the effects of change on their own welfare.

John Godfrey, associate of the Centre for Human Ecology, University of Edinburgh, is at 41 Lawford Road, London NW5 2LG, UK. 